\title{
Etnoecologia e etnobotânica em ambientes de Cerrado no Estado de Mato Grosso
}

\author{
Ethnoecology and ethnobotanic at Cerrado environments in Mato Grosso State \\ Ethnoécologie et ethnobotanique dans Cerrado environnements en Mato Grosso \\ Province
}

\author{
Etnoecología y etnobotánica en ambientes del Cerrado en el Estado de Mato Grosso \\ Flora Ferreira Camargo* \\ (florafloresta@gmail.com) \\ Thaianny Rodrigues de Souza** \\ (thaiannyrodrigues@hotmail.com) \\ Reginaldo Brito da Costa** \\ (reg.brito.costa@gmail.com)
}

Recebido em 22/07/2013; revisado e aprovado em 15/12/2013; aceito em 10/04/ 2014

Resumo: O presente artigo objetivou mostrar a utilização da etnoecologia, etnobotânica e o etnoconhecimento em
comunidades locais do Estado de Mato Grosso, com foco no saber popular sobre plantas do bioma Cerrado.
Palavras-chave: Etnoconhecimento. Diversidade biológica. Comunidade local.
Abstract: Goal of this study was to demonstrate the utilization of ethnoecology, ethnobotanic and ethno-knowledge
at local communities in Mato Grosso State, focusing popular knowledge about plants of the Cerrado biome.
Key words: Ethno-knowledge. Biological diversity. Local community.
Résumé: Le but de cette étude était de démontrer l'utilisation de l'ethnoécologie, ethnobotanique e l'ethno-con-
naissance dans communautés locales en Mato Grosso Province mettant l'accent sur les savoirs populaires sur les
plantes du biome Cerrado.
Mots-clés: Ethno connaissance. Diversité biologique. Communauté local.
Resumen: El presente artículo tiene como objetivo mostrar el uso de etnoecología, etnobotánica y el etnoconoci-
miento en cumunidades locales del Estado de Mato Grosso, con el foco (centrándose) en el saber popular sobre las
plantas del bioma Cerrado.
Palabras clave: Etnoconocimiento. Diversidad biológica. Comunidad local.

\section{Introdução}

A etnoecologia contribui para a construção de um novo paradigma de desenvolvimento sustentável investigando formas peculiares de conhecimento ecológico e a classificação, interpretação e manejo da natureza, não sendo restritos ou originários apenas do saber sistematizado, mas científico (TOLEDO, 1992). Estudos etnoecológicos são de extrema relevância para compreendermos as interações entre os seres humanos e o ambiente natural, enfatizando as relações do conhecimento entre as populações e o seu ambiente, baseado nas experiências de gerações passadas.

Conforme Pedroso Júnior (2002), os estudos etnoecológicos têm buscado conciliar a conservação dos ecossistemas com o desenvolvimento socioeconômico e a melhoria da qualidade de vida das parcelas menos favorecidas de nossa população e, segundo Nordi et al. (2001); "a etnoecologia tem a função de desvendar, compreender e sistematizar, cientificamente todo um conjunto de teorias e práticas relativas ao ambiente, oriundas de experimentação empírica do mesmo por culturas tradicionais, indígenas ou autóctones".

Os estudos etnoecológicos devem ser norteados por duas premissas: uma de caráter filosófico ou ideológico e outra, intrinsecamente relacionada, de caráter prático. A primeira trata da promoção do respeito à diversidade cultural, eliminando posturas etnocêntricas, e a segunda diz respeito à utilização de práticas tradicionais como exemplos de desenvolvimento sustentável não excludente (NORDI et al., 2001).

Para Guarim Neto e Carniello (2007), a interdependência entre os seres, o ambiente

\footnotetext{
* Universidade Federal de Lavras, Lavras, MG, Brasil

** Universidade Federal de Mato Grosso, Cuiabá, MT, Brasil.
} 
e a base interdisciplinar é que deve fundamentar estudos voltados para o etnoconhecimento para desvendar e entender o saber local acumulado através das gerações. Esses pressupostos devem contribuir para as novas pesquisas etnoecológicas em aspecto mais amplo e, mais especificamente, aquelas desenvolvidas no cerrado mato-grossense, podendo assim auxiliar e subsidiar novos projetos e estudos no âmbito regional.

No Estado de Mato Grosso, já se tem hoje estudos e pesquisas em muitas comunidades, objetivando também a formação de recursos humanos em diferentes níveis (iniciação científica, mestrado e doutorado), como indicadores de um banco de dados sobre o etnoconhecimento voltado para os recursos vegetais (GUARIM NETO; CARNIELLO, 2007). Tal diversidade está intimamente relacionada com a própria extensão territorial, privilegiada com complexidade de biomas e rica diversidade étnica e cultural que favorecem estudos na área.

Este estudo não tem um caráter definitivo nem possui a pretensão de esgotar o assunto, porém a de mostrar a utilização da etnoecologia, etnobotânica e o etnoconhecimento em comunidades locais do Estado de Mato Grosso, com foco no saber popular sobre plantas do bioma cerrado.

\section{O Cerrado, seus recursos e algumas caracterizações}

O cerrado possui tipologias desde campo limpo até cerradão, apresentando floresta decídua na encosta dos morros e floresta de galeria ao longo dos rios, além de, em alguns trechos, vegetação típica de áreas alagadas. As principais atividades econômicas são a agricultura familiar, a pesca, a fabricação de farinha de mandioca para consumo próprio e comercialização; algumas atividades ligadas ao turismo começam a ser implantadas e, nos anos recentes, as influências externas vêm se tornando marcantes, aprofundadas pela implantação de infraestrutura moderna, que permite a rápida penetração na área da ideologia urbano-industrial (AMOROZO, 2006).

Guarim Neto (2001) chama a atenção para o cerrado no Estado do Mato Grosso, argumentado que o bioma está repleto de possibilidades de aproveitamento dos recursos vegetais, sendo as populações locais detentoras desse conhecimento botânico e que utilizam esses recursos.

Um dos grandes problemas das comunidades tradicionais do Centro-Oeste do Brasil atualmente é a ausência de segurança alimentar, demonstrada pela falta de mecanismos que promovam a geração de renda e a pressão do agronegócio sobre a biodiversidade. Nesse contexto, o cerrado apresenta uma grande riqueza de espécies negligenciadas que podem ser consideradas "plantas do futuro" (VIEIRA et al., 2010).

Os recursos vegetais do cerrado possuem papel importante na vida dos membros da comunidade pela diversidade de usos, manifestada na quantidade de espécies potencialmente econômicas o que inclui as alimentícias, artesanal, medicinais, forrageiras, madeireiras, oleíferas, entre outras. Em estudos conduzidos por Carniello et al. (2010) em Mirassol D'Oeste, as espécies vegetais encontradas nos quintais da população possuem vários usos, como auxílio na alimentação humana e animal, artesanatos, medicinal, ornamental, tóxico entre outros, porém o mais importante é a complementação alimentar, reduzindo os custos alimentícios familiares. Em comunidades estudadas em Rondonópolis por Pasa e Ávila (2010), verificou-se que mais de 30\% das espécies cultivadas são nativas da região de cerrado e mais usadas como complemento alimentar, medicamentos, lenha e ornamental. A riqueza de espécies da flora e fauna do cerrado é expressiva, representando cerca de $30 \%$ da biodiversidade brasileira (EITEN, 1972; RIBEIRO; WALTER, 1998).

O cerrado brasileiro está entre os biomas de maior diversidade florística do planeta (MENDONÇA et al., 2000). Entretanto, em função da facilidade de desmatamento, boas condições de topografia, histórico de colonização e tipo de terreno, o cerrado é a principal região brasileira produtora de grãos e gado de corte provindos do latifúndio. Com a ocupação das terras do cerrado para a produção agrícola mecanizada, as áreas nativas vêm sendo removidas em um ritmo acelerado e desordenado (AGUIAR; CAMARGO, 2004). Myers et al. (2000) pontuam que nada menos do que $80 \%$ da área original do cerrado foram antropizadas, restando apenas $20 \%$ de áreas consideradas originais ou pouco perturbadas. 
Tal situação, por exemplo, pode ser percebida nos remanescentes de cerrado nos municípios em que os estudos etnoecológicos vêm sendo realizados, onde a necessidade de implantação de unidades de conservação de uso sustentável é extremamente necessária e urgente.

Para demonstrar a importância de estudos etnoecológicos, Amaral (2008), Carvalho et al. (2011), Guarim Neto et al. (2011) e Xavier et al. (2011) constataram a utilização das espécies do cerrado com diversas finalidades: a) aromáticas usadas para realçar o sabor dos alimentos: cumbaru (Dypterix alata Vogel), hortelã (Hypis cana Pohl ex. Benth), carne de vaca (Roupala brasiliensis Klotzsch), cidreirada-mata (Siparuna cuyabensis Aublet); plantas medicinais: quina (Strychnos pseudoquina A. St.-Hil.), arnica (Camarea ericoides A. St.-Hil.), mangava-brava (Lafoensia pacari A. St.-Hil.), araticum-do-cerrado (Annona coriacea Mart.), pata-de-vaca (Bauhinia rufa (Bong.) Steud), sangra d'água (Croton urucurana Baillon); b) utilização de frutos tais como: a cagaita (Eugenia dysenterica DC.), a mangaba (Hancornia speciosa B.A. Gomes) o pequi (Caryocar brasiliense Cambess.), buriti (Mauritia flexuosa L.), maracujá-do-cerrado (Passiflora campestris Rodr.), jenipapo (Genipa americana L.), c) o uso de lenha: a semaneira (Byrsonima coccolobifolia Kunth, Byrsonima verbascifolia (L.) Rich. ex Juss.), o angico (Anadenanthera falcata (Benth.) Speg.) e, d) fabricação de utensílios domésticos como peneiras e vassouras, utilizando o buriti (Mauritia flexuosa L.) e a bocaiúva (Acrocomia aculeata (Jacq.) Lodd. ex Mart.).

A busca da lenha no cerrado em geral é uma atividade feminina, na qual as mulheres coletam ramos caídos no solo, confeccionando feixes desse material, que são amarrados e carregados até a moradia sob os braços ou cabeça, esta protegida por pequena rodilha de tecido, para não causar ferimentos.

A relação com o meio ambiente está alicerçada na subsistência e no uso de diferentes tipos de unidades de paisagem, e sua integração com a natureza proporciona várias práticas e atividades, de forma a maximizar o uso desses ambientes, como a extração e coleta dos recursos vegetais, pesca, caça, agricultura diversificada e pecuária de pequena escala. Esse saber sobre os recursos vegetais do cerrado é fruto de suas adaptações e interações com o ecossistema, conhecimento adquirido por meio de observações e experimentação, que gera um saber ecológico que é materializado em suas práticas cotidianas.

Moreira e Guarim Neto (2009), demonstrando a importância da relação dessas comunidades com os recursos naturais do cerrado, analisaram e utilizaram os dados referentes à vegetação local no município de Rosário Oeste, partindo da percepção da classificação oral das comunidades. No que se refere às unidades de paisagem do cerrado, seis tipos de fisionomias vegetais foram detectadas: "Cerrado de pedra", "Cerrado de areia", "Mata", "Várzea", "Chapada" e "Campo". Nesse mesmo estudo em relação à caracterização das unidades de paisagens do cerrado observou-se que os membros da comunidade usam a palavra "mato" para designar a vegetação. Então, quando se perguntava: "quais os tipos de mato que tem por aqui?", eles indicam: "cerrado", "mata", "várzea", "chapadão" e "campo" para distinguir os tipos de vegetação, classificando o cerrado em dois tipos; o "Cerrado de pedra" e o "Cerrado de areia".

Pasa (2011), estudando uma comunidade situada na região da baixada cuiabana, onde não há estação de tratamento de esgoto e água, posto de saúde, hospitais e farmácias, além de algumas residências não possuírem energia elétrica, ressalta a importância da vegetação de mata de galeria localizada na região, onde é considerada como fonte de recursos naturais, principalmente para uso medicinal, sendo de suma importância para os moradores da região, resultando na conservação dessa vegetação.

As comunidades desenvolveram ao longo do tempo uma multiutilização do ambiente, manipulando a paisagem natural, porém mantendo a heterogeneidade de habitats e ampliando o uso da variabilidade biológica. O multiuso que fazem do cerrado proporciona adaptações às condições ambientais e às variações sazonais, requerendo um manejo adaptativo ecológico, de forma que desenvolveram um profundo conhecimento dos recursos e de seus ciclos ecológicos de renovação.

As pesquisas etnoecológicas, e ainda mais evidentes nas etnobotânicas realizadas na região, mostram que esses conhecimentos passados de geração para geração e os 
recursos naturais encontram-se ameaçadas pelo desmatamento.

Essas mudanças começam a ser sentidas, perceptíveis na afirmação dos entrevistados de que muitas das espécies nativas de cerrado estavam se tornando difíceis de encontrar, seja pela destruição dos habitats para formação de pastagens ou uso urbano, seja pela sua inacessibilidade, devido à apropriação e cercamento das terras por indivíduos estranhos às comunidades. Também, a "modernização" traz consigo novas opções de cuidados com a saúde e certa desvalorização da cultura local, à qual os jovens são o grupo mais sensível, reforçando a tendência de perda ou abandono das práticas tradicionais, as relações com a roça e com a mata de galeria, festas, danças e crenças (RIBEIRO et al., 2009).

Em estudos realizados por Amorozo (2002) em Santo Antônio do Leverger, a área caracteriza-se por uma situação sócioeconômica em transformação. Questões muito importantes ligadas à saúde e doenças são refletidas pelo confronto entre os modos de pensar e agir tradicionais e as novas ideias e costumes, trazidos com o contato intensificado nas décadas recentes com a sociedade nacional.

A comunidade de Conceição-Açu, no município de Cuiabá, MT, entende os recursos vegetais dentro de um significado amplo de utilidade, apresentando uma dependência dos recursos localmente disponíveis, especialmente de plantas medicinais, na mata de galeria e alimentar, nas roças e quintais. Os usos descritos para a mata de galeria revelam expressivo aproveitamento em relação às funções de coleta, demonstrando preocupação com a manutenção das potencialidades vegetais, contribuindo dessa forma para a conservação da biodiversidade nos ecossistemas naturais (PASA et al., 2005).

A presença da mata de galeria, particularmente no cerrado mato-grossense, tem grande importância na vida da população regional. De um lado, pela oferta de remédios e alimentos para subsistência das famílias, de outro, por ser um dos vetores que leva determinados moradores locais à conservação dos recursos nela existentes e, com ela identifica-se socialmente, enquanto membro da comunidade.

Como já foram mencionados, os quintais também podem ser ricos depositários de germoplasmas. Na cidade de Santo Antônio do Leverger, em Mato Grosso, um único quintal, com menos de meio hectare, continha mais de cem tipos diferentes de plantas (entre espécies e variedades reconhecidas localmente). Em sua maioria, são espécies de uso alimentar e/ou medicinal. As fruteiras apresentavam a maior riqueza, entre espécies e variedades; só de bananeiras, havia sete tipos diferentes, enquanto se contavam 11 tipos de cítricos. Algumas das plantas faziam parte da vegetação nativa local. Este quintal tem mais de 90 anos de existência, segundo os cálculos do agricultor proprietário.

\section{Diversidade biológica e os estudos da etnoecologia no Estado de Mato Grosso}

O Estado de Mato Grosso está inserido na região Centro-Oeste do Brasil, é caracterizado pelas formações biogeográficas do cerrado, do pantanal e da floresta amazônica. Seus recursos naturais são usados tradicional e contemporaneamente sob diferentes formas pelas populações humanas que habitam esses locais de alta diversidade, distribuídos pelo território mato-grossense.

Essa diversidade propicia uma quantidade grande de habitats diferenciados abrigando uma variedade imensa de espécies com características próprias e específicas ao seu ambiente. Essa diversidade de condições bióticas e abióticas faz com que as comunidades humanas presentes na região possam também caracterizar-se e expressar-se de formas bastante distintas dependendo das condições de cada sub-região ou município. Mato Grosso possui uma variedade de múltiplas manifestações culturais diversificadas, cada qual com um ambiente bastante peculiar de ocupação (MORAIS, 2003). Conservar a biodiversidade presente nesse bioma nos dias de hoje é um grande desafio.

De acordo com Neuburger (2003), a incorporação definitiva de Mato Grosso à economia nacional se deu somente nos anos 70 do século XX, através de um boom regional, iniciado pela implantação de uma rede rodoviária, pelos baixos preços da terra, pela colonização particular por empresas sulistas e pela migração crescente de colonos do Sul do país e, com isso, áreas enormes de cerrado foram desmatadas, deslocando e expulsando 
os grupos tradicionais e indígenas. Os espaços sociais dos camponeses, ribeirinhos, quilombolas e dos grupos indígenas voltados à produção de subsistência podem ser considerados como regiões de exclusão, tendo o êxodo rural como a expressão da degradação sociocultural e ambiental.

A maioria dos grupos marginalizados quase sempre fracassa nas suas estratégias de integração por falta de recursos econômicos, socioculturais e ambientais, não podendo adaptar seu modo de vida às exigências da lógica do mercado, perdendo ao longo do tempo sua cultura e conhecimento. Nesse sentido, configura-se a importância dos estudos etnoecológicos.

No Estado de Mato Grosso, em outras regiões brasileiras e no exterior, a materialidade do conhecimento de populações em relação ao componente vegetal, por exemplo, tem geralmente sido registrada nos espaços de entorno das moradias que contemplam várias formas de manejo e localização e as denominações desses espaços de um grupo cultural para o outro (CARNIELLO et al., 2002). Nesses espaços, é encontrada uma diversidade de espécies que configuram um importante patrimônio genético, no qual o componente vegetal e animal e a cultura local constituem um sistema coexistente através de conhecimentos acerca da relação entre populações humanas, vegetais e animais refletindo a história de relações e de grupos sociais (AMOROZO, 2006). Tal diversidade está intimamente relacionada com a própria extensão territorial do Estado de Mato Grosso, privilegiada com a complexidade de biomas e rica diversidade étnica e cultural, os quais favorecem estudos na área.

Ao longo das últimas décadas, pôdese testemunhar que estudos e pesquisas em etnoecologia, principalmente através da etnobotânica, apresentaram um volume maior de trabalhos culminando com o início dos trabalhos com plantas medicinais, intensificados a partir da década de 1980 com abordagens envolvendo: as comunidades e o respectivo acervo de conhecimento de natureza concreta e simbólica, os saberes acumulados de seres humanos individualmente (benzedeiras, raizeiros, pescadores, agricultores, pecuaristas tradicionais e outros) cuja atividade que desenvolvem e acumulam propicia-lhes um vasto conhecimento a respeito da ocorrência, manejo e conservação dos recursos vegetais, $\mathrm{o}$ contato de diferentes culturas com unidades de paisagens naturais (em diferentes biomas e regiões) e artificiais (roças, pastagens, quintais e hortas) (MORAES, 2003).

Ainda de acordo com Moraes (2003), percebe-se também que os trabalhos em etnoecologia iniciam-se mais tarde, já na segunda metade da década de 90, quando o seu objeto de estudo é mais bem caracterizado, diferindo-se da etnobotânica, período em que se cria o curso de Mestrado em Ecologia e Conservação da Biodiversidade, do Instituto de Biociências da Universidade Federal de Mato Grosso.

Atualmente a área de etnobotânica no estado já se constitui um relevante banco de dados sobre o etnoconhecimento no bioma cerrado, com bases científicas e provindos de estudos e pesquisas em muitas comunidades, objetivando formar recursos humanos em diferentes níveis e também poder subsidiar a definição de políticas públicas destinadas aos respectivos locais e comunidades, assim como, em seu conjunto, diminuir os impactos socioambientais e orientar a definição de áreas prioritárias para atuação e de conservação no estado. Porém ainda percebe-se a necessidade de assimilação e atuação em estudos etnoecológicos em um maior número de instituições de pesquisa e ensino no estado.

A cidade de Cuiabá, capital do estado, sediou em 2002 o I Seminário Mato-Grossense de Etnobiologia e Etnoecologia e II Seminário Centro-Oeste de plantas medicinais, ocorrido de 25 a 28 de outubro de 2002. Desse importante espaço, surgiu um coletânea de artigos "Diversos olhares em etnobiologia, etnoecologia e Plantas medicinais" caracterizados por grande diversidade de temas expressando diversos olhares e de grande contribuição para a ciência da etnoecologia no estado. E, em 2005, o município de Chapada dos Guimarães sediou o V Simpósio Brasileiro de Etnobiologia e Etnoecologia "Diversidade de saberes e práticas", ocorrido de 15 a 19 de dezembro de 2004. Hoje Mato Grosso representa a Sociedade Brasileira de Etnobiologia e Etnoecologia na Região Centro-Oeste do Brasil.

A Universidade Federal de Mato Grosso sedia dois grupos de pesquisa em etnoecologia cadastrados no CNPq: o Estudando o 
Cerrado (ESCER), de repercussão Etnobiológica, Etnobotânica e Etnozoológica, que objetiva resgatar os fatos e realizações socioculturais, botânicos e zoológicos em comunidades de saber local abordando a interação ser humano-ecologia-biologia, situadas no município de Rondonópolis; e o Grupo de Estudos da Flora, Vegetação e Etnobotânica (FLOVET), que vem realizando no espaço territorial mato-grossense, ao longo de quase trinta anos, estudos e pesquisas em um universo extenso no cenário das suas paisagens, envolvendo o cerrado em aspectos que mostram a diversificação e riqueza dessa região, inserida na região Centro-Oeste, abrangendo populações humanas e etnoconhecimento, divulgando seus trabalhos, até então disseminados em eventos e periódicos nacionais e internacionais, e lança seu boletim periódico no ano de 2009.
Os municípios incluídos nesta pesquisa considerando o conhecimento etnoecológico em comunidades rurais, urbanas, ribeirinhas e indígenas de relevância para o presente estudo são: Acorizal, Barra do Bugres, Barão de Melgaço, Cáceres, Cuiabá, Chapada dos Guimarães, Campo Verde, Colíder, Dom Aquino, Santo Antonio do Leverger, Novo São Joaquim, Primavera do Leste, Poxoréu, Santo Antonio do Leste, Mirassol D'Oeste, Rosário Oeste, Rio Branco, Juscimeira, Rondonópolis, Nova Xavantina, Várzea Grande, Poconé, Jangada, Canarana, Novo Santo Antônio, Jaciara, Nossa Senhora do Livramento, Vila Bela de Santíssima Trindade, Barra do Garças, Ribeirão Cascalheira e Pedra Preta.

No sentido de facilitar a visualização e os locais onde foram desenvolvidos os trabalhos com seus respectivos autores e títulos, apresenta-se a Tabela 1.

Tabela 1 - Autores, ano, título e local de trabalhos relacionados ao estudo da etnoecologia.

\begin{tabular}{|c|c|c|}
\hline Autores / Ano & Título & Local \\
\hline $\begin{array}{l}\text { Amaral e Guarim Neto, } \\
2008\end{array}$ & $\begin{array}{l}\text { Os quintais como espaços de conservação e } \\
\text { cultivo de alimentos: um estudo na cidade de } \\
\text { Rosário Oeste (Mato Grosso, Brasil). }\end{array}$ & Mato Grosso, Brasil \\
\hline Amorozo, 2002 & $\begin{array}{l}\text { Uso e diversidade de plantas medicinais em } \\
\text { Santo Antônio do Leverger,MT. }\end{array}$ & Mato Grosso, Brasil \\
\hline Carniello et al., 2010 & $\begin{array}{l}\text { Quintais urbanos de Mirassol D'Oeste, MT, } \\
\text { Brasil: uma abordagem etnobotânica. }\end{array}$ & Mato Grosso, Brasil \\
\hline Mendonça et al., 2000 & $\begin{array}{l}\text { Florística da região do Espigão Mestre do São } \\
\text { Francisco, Bahia e Minas Gerais. }\end{array}$ & $\begin{array}{l}\text { Bahia e Minas } \\
\text { Gerais, Brasil }\end{array}$ \\
\hline $\begin{array}{l}\text { Moreira e Guarim Neto, } \\
2009\end{array}$ & $\begin{array}{l}\text { Usos múltiplos de plantas do cerrado: um } \\
\text { estudo etnobotânico na comunidade Sítio } \\
\text { Pindura, Rosário Oeste, Mato Grosso, Brasil. }\end{array}$ & Mato Grosso, Brasil \\
\hline Neubeurger, 2003 & $\begin{array}{l}\text { Estratégias de Ssrevivência entre tradição e } \\
\text { inovação - exemplos da produção familiar em } \\
\text { Mato Grosso, Brasil. }\end{array}$ & Mato Grosso, Brasil \\
\hline Pasa, 2011 & $\begin{array}{l}\text { Saber local e medicina popular: a etnobotânica } \\
\text { em Cuiabá, Mato Grosso, Brasil. }\end{array}$ & Mato Grosso, Brasil \\
\hline Pasa e Ávila, 2010 & $\begin{array}{l}\text { Ribeirinhos e recursos vegetais: a etnobotânica } \\
\text { em Rondonópolis, Mato Grosso, Brasil. }\end{array}$ & Mato Grosso, Brasil \\
\hline Pasa et al, 2005 & $\begin{array}{l}\text { Estudo etnobotânico na comunidade de } \\
\text { Conceição-Açu (alto da bacia do rio Aricá-Açu, } \\
\text { MT, Brasil). }\end{array}$ & Mato Grosso, Brasil \\
\hline
\end{tabular}




\section{Considerações finais}

Atualmente, priorizando uma transmissão e interlocução de saberes e práticas, os diferentes estudos etnoecológicos são realizados em vários ecossistemas e comunidades neles existentes, objetivando a busca da preservação e resgate de tradições locais em uma diversidade de situações e ambientes ecológicos que estão sendo devastados paulatinamente.

Portanto as informações contidas no artigo mostram a importância e a carência de mais informações sobre o modo como as comunidades tradicionais manejam, conservam e enriquecem a biodiversidade e suas influências também na distribuição de plantas e animais e qual a sua matriz produtiva. Os estudos que buscam o registro e a compreensão da prática tradicional desses povos que é repassada através da experiência deixada como herança de geração a geração, constituem-se importantes ferramentas para a conservação dos recursos naturais principalmente no cerrado, região biogeográfica fadada à exaustão de seus recursos naturais.

Estudos dentro dessa perspectiva não podem estar ausentes das discussões sobre o meio ambiente e suas alterações. A valorização da cultura, de crenças, lendas e formas de uso dos recursos que permeiam o saber local fundamenta o conhecimento ecológico tradicional, no qual está baseada a ciência da etnoecologia, que faz a integração deste com o conhecimento ecológico científico, enfatizando então a diversidade biocultural.

E a contribuição dos pesquisadores deve ir além da documentação como ferramenta de fixação das famílias em suas comunidades, assim como persistir na luta por unidades de conservação de uso sustentável e políticas públicas que busquem caracterizar essas comunidades como as próprias mantenedoras dos recursos naturais no Estado de Mato Grosso.

\section{Referências}

AGUIAR, L. M. S.; CAMARGO, A. J. A. Cerrado: ecologia e caracterização. Planaltina, DF: Embrapa Informação Tecnológica, 2004. 249p.

AMARAL, C. N; GUARIM NETO, G. Os quintais como espaços de conservação e cultivo de alimentos: um estudo na cidade de Rosário Oeste (Mato Grosso, Brasil).
Bol. Mus. Para. Emílio Goeldi. Ciências Humanas, Belém, PA, v. 3, n. 3, p. 329-341, set./ dez. 2008.

AMARAL, C. N. Recursos vegetais dos tradicionais quintais de Rosário Oeste - Mato Grosso. 2008. 80p Dissertação (Mestrado em Ecologia e Conservação da Biodiversidade) - Instituto de Biociências, Universidade Federal de Mato Grosso, Cuiabá, 2008.

AMOROZO, M. C. M. Uso e diversidade de plantas medicinais em Santo Antônio do Leverger, MT, Brasil. Acta bot. bras., São Paulo, v. 16(2), p. 189-204, 2002.

Agricultura tradicional, espaços de resistência e o prazer de plantar. In: ALBUQUERQUE, U. P. et al. (Org.). Atualidades em etnobiologia e etnoecologia. 2. ed. Recife: Recife: NUPEEA/Sociedade Brasileira de Etnobiologia e Etnoecologia, 2006. Vol. 1, p. 123-131.

CARNIELLO, M. A.; SILVA, R. S.; CRUZ, M. A. B.; GUARIM NETO, G. Quintais urbanos de Mirassol D'Oeste-MT, Brasil: uma abordagem etnobotânica. Acta Amazônica, Manaus, v. 40(3), p. 451-470, 2010.

CARNIELLO, M. A.; SANTOS-SILVA, R. dos; CABRAL, C. D. de O. Estudo da composição florística dos quintais de Cáceres-MT. Relatório Final do Projeto Bases Sócioambientais para o Planejamento Urbano de Cáceres-MT (FAPEMAT 2000-2002), 2002. 27p.

CARVALHO, J. V. F.; GUARIM NETO, G.; GUARIM, V. L. M. S.; FERREIRA, H. Plantas aromáticas no cerrado. In: GUARIM NETO, G.; CARVALHOR, J. V. F. (Org.). Biodiversidade matogrossense: as plantas e suas potencialidades. Cuiabá: Carlini \& Caniato Editorial, 2011. p. 15-40.

EITEN, G. The cerrado vegetation of Brazil. Botanical Review, Brasília, v. 38, n. 2, p 201-341, 1972.

GUARIM NETO, G. Flora medicinal, populações humanas e o ambiente de cerrado. Horticultura brasileira, Brasília, v. 19, p. 203-206, 2001.

GUARIM NETO, G.; CARNIELLO, M. A. Etnoconheciemnto e saber local: um olhar sobre populações humanas e os recursos vegetais. In: ALBUQUERQUE, U. P de; ALVES, A. G. C.; ARAUJO, T. A. S. (Org.). Povos e paisagens: etnobiologia, etnoecologia e biodiversidade no Brasil. Recife: NUPEEA/UFRPE, 2007. p. 105-114.

GUARIM NETO, G.; CARVALHO, J. V. F.; MORAES, A. J. F.; FERREIRA, H. Frutos comestíveis no cerrado. In: GUARIM NETO, G.; CARVALHO, J. V. F. (Org.). Biodiversidade matogrossense: as plantas e suas potencialidades. Cuiabá: Carlini \& Caniato Editorial, 2011. p 41-72.

MENDONÇA, R. C.; FELFILI, J. M.; SILVA JÚNIOR, M. C.; FAGG, C.W.;SILVA, M. A.; FILGUEIRAS, T.S.;WALTER, B. M. T. Florística da região do Espigão Mestre do São Francisco, Bahia e Minas Gerais. Boletim do Herbário Ezechias Paulo Heringer, Brasília, n. 6, p. 38-94, 2000.

MYERS, N.; MITTERMEIER, R. A.; MITTERMEIER, C. G.; FONSECA, G. A. B.; KENT, J. Biodiversity hotspots for conservation priorities. Nature, n. 403, p. 853-858, February 2000.

MORAES, R. G. Plantas medicinais e representações sobre saúde e doenças na Comunidade de Angical (Rosário Oeste, MT). 2003. 153p. Dissertação (Mestrado em Saúde e Ambiente) - Instituto de Saúde Coletiva, Universidade Federal de Mato Grosso, Cuiabá, 2003. 
MOREIRA, D. L.; GUARIM NETO, G. Usos múltiplos de plantas do cerrado: um estudo etnobotânico na comunidade sítio pindura, Rosário Oeste, Mato Grosso, Brasil. Polibotânica, México, n. 27, p. 159-190, 2009.

NEUBURGER, M. Estratégias de sobrevivência entre tradição e inovação - exemplos da produção familiar em Mato Grosso, Brasil. Actas latinoamericanas de Varsovia, v. 26, 2003.

NORDI, N.; THÉ, A. P. G.; MOURÃO, J. S.; MADI, E. F.; CAVALLINI, M.; MONTENEGRO, S. C. S. Etnoecologia, educação ambiental e desenvolvimento sustentável. In: SANTOS, J. E.; SATO, M. A contribuição da educação ambiental à Esperança de Pandora. São Carlos: RIMA, 2001. p. 133-144.

PASA, M. C. Saber local e medicina popular: a etnobotânica em Cuiabá, Mato Grosso, Brasil. Bol. Mus. Para. Emílio Goeldi. Cienc. Hum., Belém, PA, v. 6, n. 1, p. 179196, jan./abr. 2011.

PASA, M. C.; ÁVILA, G. Ribeirinhos e recursos vegetais: a etnobotânica em Rondonópolis, Mato Grosso, Brasil. Interações, Campo Grande, MS, v. 11, n. 2, p. 195-204, jul./dez. 2010.

PASA, M. C.; SOARES, J. J.; GUARIM NETO, G. Estudo etnobotânico na comunidade de Conceição-Açu (alto da bacia do rio Aricá-Açu, MT, Brasil). Acta bot. Bras., São Paulo, v.19, n. 2, p. 195-207, 2005.

PEDROSO JUNIOR, N. Etnoecologia e conservação em áreas naturais protegidas: incorporando o saber local na manutenção do Parque Nacional do Superagui. 2002. 80p. Dissertação (Mestrado) - Universidade Federal de São Carlos, São Carloos, SP, 2002.

RIBEIRO, J. F.; WALTER, B. M. T. Fitofisionomias do bioma cerrado. In: SANO, S. M.; ALMEIDA, S. P. (Ed.). Cerrado: ambiente e flora. Planaltina, DF: Embrapa Cerrados, 1998. p. 89-166.

RIBEIRO, R. S. C.; MIRANDA, A. F.; GUARIM NETO, $\mathrm{G}$. Etnoecologia e recursos vegetais na comunidade ribeirinha de Passagem da Conceicão, Várzea Grande, MT. 2009. Dissertação (Mestrado em Ecologia e Conservação da Biodiversidade) - Instituto de Biociências, Universidade Federal de Mato Grosso, Cuiabá, 2009.

TOLEDO, $\mathrm{V}$. What is ethnoecology? origins, scope and implications of a rising discipline. Etnoecologica, v. 1, n.1, 1992.

VIEIRA, R. F.; AGOSTINI-COSTA, T. S.; SILVA, D. B.; SANO, S. M.; FERREIRA, F. R. Espécies de maior relevância para a região Centro-Oeste. In: VIEIRA, R. F.; AGOSTINICOSTA, T. S.; SILVA, D. B.; SANO, S. M.; FERREIRA, F. R. Frutas nativas da região Centro- Oeste. Brasília: EMBRAPA Informação Tecnológica, 2010, 322p.

XAVIER, F. F.; GUARIM NETO, G.; GUARIM, V. L. S.; FERREIRA, H.; Plantas medicinais no cerrado. In: GUARIM NETO, G.; CARVALHO, J. V. F. (Org.). Biodiversidade matogrossense: as plantas e suas potencialidades. Cuiabá: Carlini \& Caniato Editorial, 2011. p 93-112. 